\title{
Arrive: A retrospective registry of Indian patients with venous thromboembolism
}

\author{
Dhanesh R. Kamerkar, M. Joseph John', Sanjay C. Desai², Liesel C. Dsilva³, Sadhna J. Joglekar4
}

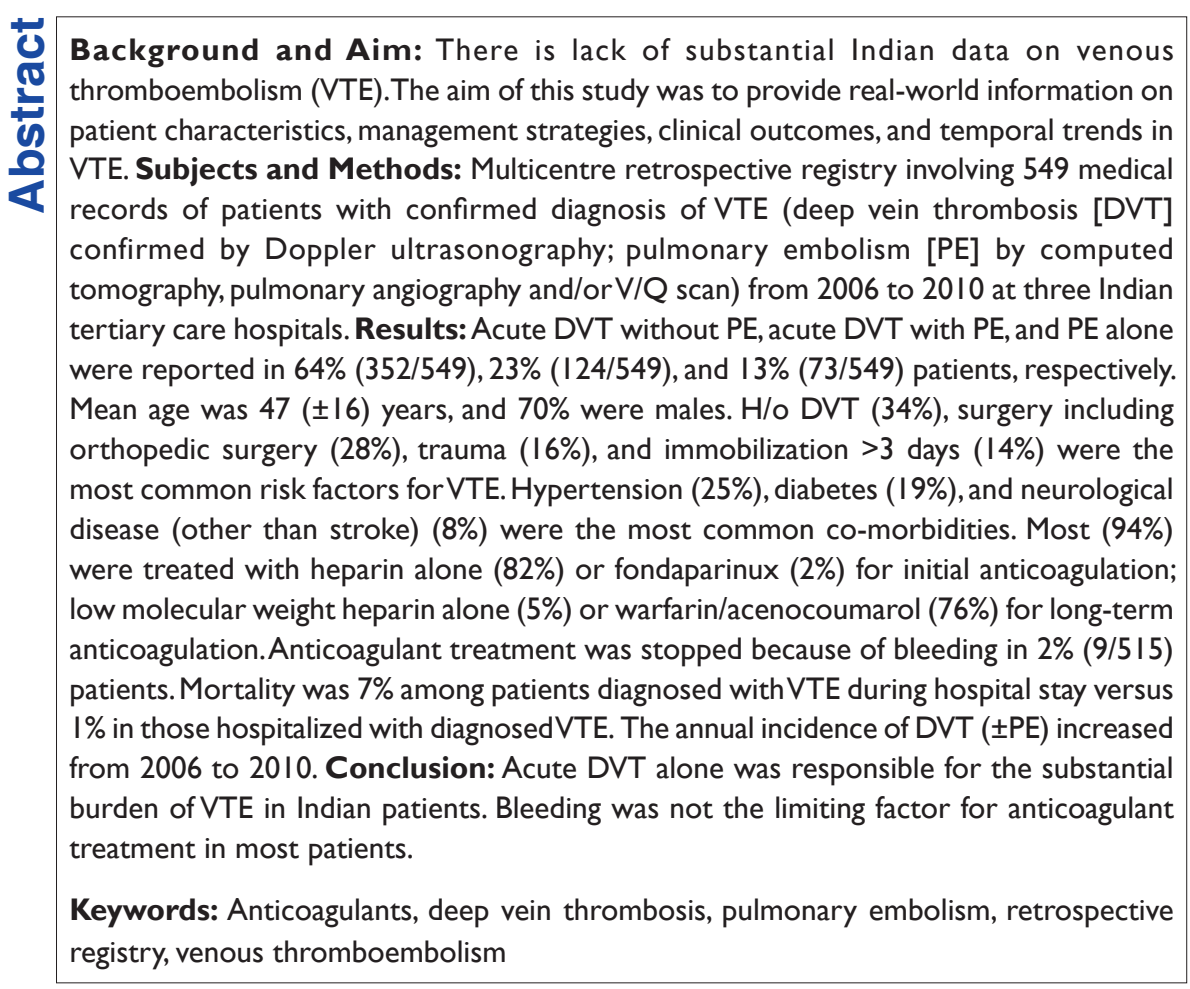

\begin{tabular}{|l|}
\hline Access this article online \\
\hline Website: www.ijccm.org \\
\hline DOI: 10.4103/0972-5229.178178 \\
\hline Quick Response Code: \\
\hline
\end{tabular}

\section{Introduction}

Venous thromboembolism (VTE) comprising of deep vein thrombosis (DVT) and pulmonary embolism (PE) can result in significant mortality, morbidity, and healthcare expenditure. ${ }^{[1]}$ Approximately, one-third of patients with symptomatic VTE manifests PE, whereas

From:

Department of Vascular Surgery, Ruby Hall Clinic, Pune, Maharashtra,

'Department of Clinical Haematology, Haemato-Oncology and Bone

Marrow (Stem Cell) Transplant Unit, Christian Medical College, Ludhiana,

Punjab, ${ }^{2}$ Department of Vascular and Endovascular Surgery, M S Ramaiah

Hospital, Bengaluru, Karnataka, ${ }^{4}$ Ex-Area Medical Head, Developing Countries-

Asia, GlaxoSmithKline Pharmaceuticals, Mumbai, Maharashtra, India, ${ }^{3}$ Area

Medical Lead (Respiratory), GlaxoSmithKline Pharmaceuticals, Singapore

Correspondence:

Dr. Sadhna J. Joglekar, 502 Kanchan Ganga, Subhash Road,

Vileparle (E), Mumbai 400 057, India.

E-mail: sadhnajoglekar@gmail.com two-thirds manifest DVT alone. ${ }^{[2]}$ Both DVT and PE can be clinically silent (asymptomatic) and hence not suspected. If undiagnosed, asymptomatic VTE can lead to chronic venous disease or recurrent VTE and long-term debilitating sequelae such as postthrombotic syndrome and chronic thromboembolic pulmonary hypertension. ${ }^{[3,4]}$ VTE is not only disabling but also

This is an open access article distributed under the terms of the Creative Commons Attribution-NonCommercial-ShareAlike 3.0 License, which allows others to remix, tweak, and build upon the work non-commercially, as long as the author is credited and the new creations are licensed under the identical terms.

For reprints contact: reprints@ medknow.com

How to cite this article: Kamerkar DR, John MJ, Desai SC, Dsilva LC, Joglekar SJ. Arrive: A retrospective registry of Indian patients with venous thromboembolism. Indian J Crit Care Med 2016;20:150-8. 
prolongs hospital stay and increases the cost of treatment. Along with myocardial infarction and arrhythmia (due to electrolyte imbalance), PE is one of the commonest causes of sudden unexplained deaths in hospitalized patients. ${ }^{[5]}$

It is estimated that 20 million cases of lower extremity DVT occur in the USA alone. ${ }^{[6]}$ Routine postoperative venography has shown an incidence of $60 \%$ in patients undergoing orthopedic surgery. ${ }^{[7]}$ The prevailing notion that the incidence of VTE in Asians is less than that in the Western population has been disproved by recent studies. ${ }^{[8,9]}$ The incidence of postoperative DVT in Indian patients undergoing major lower limb surgery is as high $(43.2 \%$ and $60 \%$ patients in the groups with and without prophylaxis, respectively) as seen in the Western world. ${ }^{[10]}$

Given the growing burden of VTE in India and lack of substantial Indian data on characteristics of VTE patients, use of diagnostics tools, prophylaxis, treatment options, and clinical outcomes in VTE, there was a need to systematically collect such data.

The aim of this registry was to collect "real world" data on patient characteristics, clinical outcomes, predictors of mortality in acute DVT, management strategies and temporal trends in VTE. The intent was to collect and provide data that would reflect actual day-to-day clinical practice, rather than results of highly controlled clinical trials with restricted study populations and imposed experimental intervention.

\section{Subjects and Methods}

Institutional Ethics Committee approval was obtained before initiation of data collection. Consecutive medical records of inpatients and outpatients between January 2006 and December 2010, meeting eligibility criteria (confirmed diagnosis of acute or acute-on-chronic DVT by Doppler ultrasound scan and/or PE by chest computed tomography scan, pulmonary angiography or $\mathrm{V} / \mathrm{Q}$ scan) were identified and collected from the general medical records and/or radiology departments at each of the three participating hospitals. Hospital data were used to obtain the total number of patients who were annually registered at the hospital from 2006 to 2010.

The collected information was verified against source documents. Data were managed with validated software "Oracle Clinical" (version 4.6, Oracle Health Sciences). Data were processed and analyzed using SAS (version 9.1, statistical analysis system). For the purpose of analysis, "acute-on-chronic" DVT was considered as "acute" DVT. Descriptive statistics were used to present patient characteristics, management strategies, and clinical outcomes of patients. Annual incidence rates (95\% CI) of VTE per 100,000 hospital registrations over a period of 5 years were reported for each site.

Fisher's exact test was used to determine differences in the incidence of acute DVT $( \pm \mathrm{PE})$ over the years 2006-2010. Cochran-Armitage trend test was used to examine the direction (positive or negative) of the trend.

As primary analyses were purely descriptive, no formal sample size calculations were done.

\section{Results}

A total of 949 medical records were reviewed. Information from 59\% (556/949) records was captured for the registry. The remaining 41\% (393/949) medical records were not included because they did not satisfy the inclusion criteria. Data from 99\% (549/556) of the included records were analyzed. Data from seven patients were excluded as there was no radiologically confirmed diagnosis of PE.

A total of $64 \%(352 / 549)$ patients had acute DVT without PE, 23\% (124/549) had acute DVT with PE, and $13 \%(73 / 549)$ had PE. Eighty-seven percent $(476 / 549)$ of patients had acute DVT $( \pm \mathrm{PE})$, and 36\% $(197 / 549)$ had PE ( \pm acute DVT) [Figure 1].

A total of $21 \%(115 / 549)$ of patients visited the hospitals directly without being referred by a physician. The proportion of patients referred from different medical specialties is mentioned in Table 1.

\section{Demographics and characteristics of venous thromboembolism patients}

The demographic characteristics of the VTE patients are mentioned in Table 2.

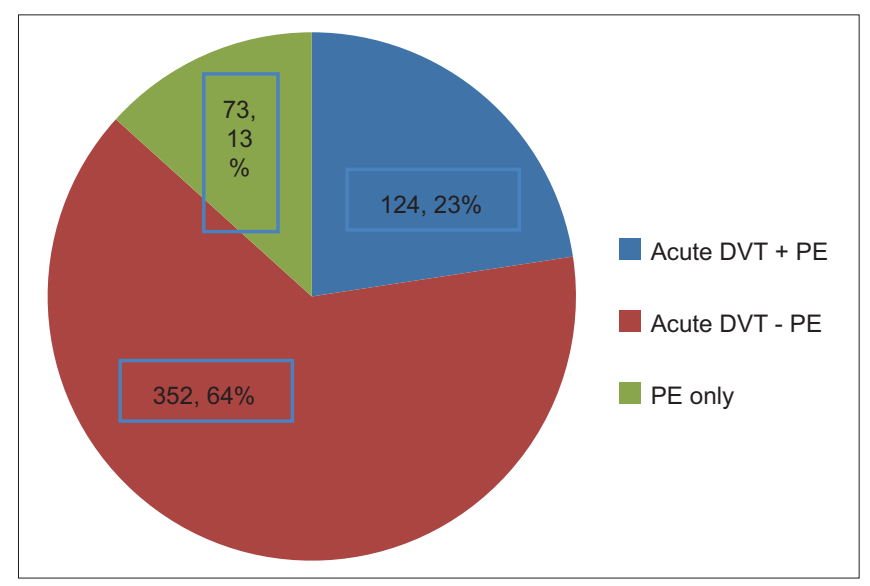

Figure I: Overall distribution of venous thromboembolism patients $(n=549)$ 


\section{Risk factors for venous thromboembolism patients}

A total of 182 patients had evidence of one risk factor, 126 had evidence of two risk factors, 70 had evidence of three risk factors and 31 had four or more risk factors

Table I: Venous thromboembolism patients referred from different medical specialties $(n=434)$

\begin{tabular}{lc}
\hline Medical specialty & Patients, $\boldsymbol{n}(\%)$ \\
\hline Cardiologist & 12 I (27.9) \\
Family physician, general physician & $95(2 \mathrm{I} .9)$ \\
Internist & $69(\mathrm{I} 5.9)$ \\
General surgeon & $27(6.2)$ \\
Neurologist & $19(4.4)$ \\
Orthopedic surgeon & $16(3.7)$ \\
Oncologist & $13(2.9)$ \\
Chest physician & $1 \mathrm{I}(2.5)$ \\
Nephrologist & $\mathrm{II}(2.5)$ \\
Gynecologist & $4(0.9)$ \\
Other* & $48(\mathrm{II} . \mathrm{I})$ \\
*Other includes referrals from the emergency department, a cardiothoracic surgeon, \\
endocrinologist, gastroenterologist, hematologist, neurosurgeon, pediatric surgeon, \\
plastic surgeon, rheumatologist, vascular surgeon or urologist, and specialty not specified
\end{tabular}

Table 2: Demographic characteristics of venous thromboembolism patients $(n=549)$

\begin{tabular}{lc}
\hline Characteristic & Patients \\
\hline Age, mean (minimum-maximum), $n(\%)$ & $46.9(9$ months-93 years) \\
Up to 39 years & $188(34.2)$ \\
$40-59$ years & $239(43.5)$ \\
$60-74$ years & $93(16.9)$ \\
$\geq 75$ years & $29(5.3)$ \\
Males, $n(\%)$ & $384(69.9)$ \\
BMI $\left(k g / m^{2}\right), n$ (mean $\left.\pm(S D)\right)$ & $48(27.9(8.6))$ \\
Tobacco consumption, $n(\%)$ & \\
Yes & $56(10.2)$ \\
No & $418(76.1)$ \\
NK* & $75(13.7)$ \\
Smoker, $n(\%)$ & \\
Yes & $39(7.1)$ \\
No & $449(81.8)$ \\
NK* & $61(1 \mathrm{I} .1)$ \\
\hline
\end{tabular}

*NK: Not known. SD: Standard deviation; BMI: Body mass index

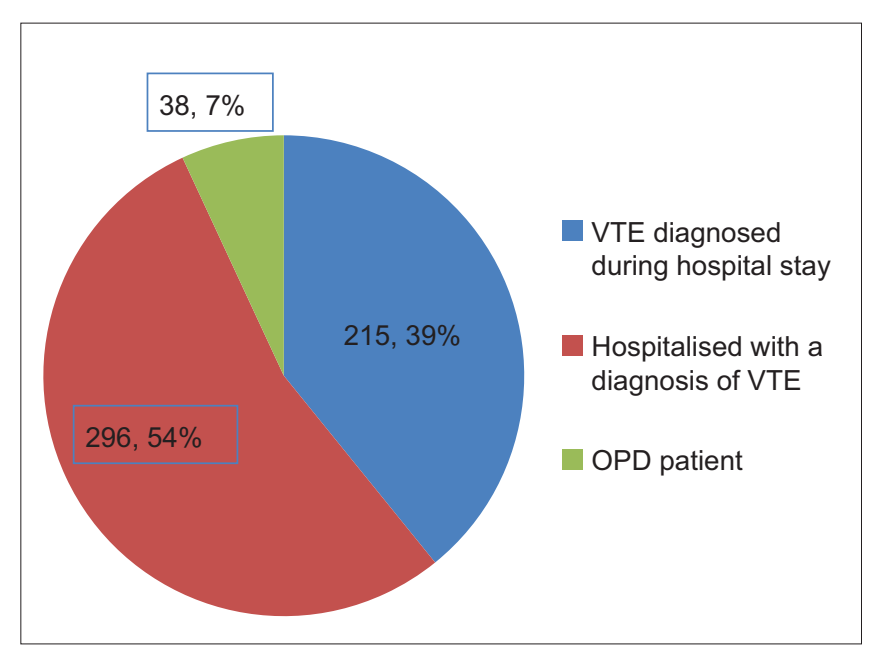

Figure 2: Place of detection of venous thromboembolism $(n=549)$ recorded. Patients undergoing orthopedic surgery constituted 22\% (33/152) of all surgical patients [Table 3].

\section{Co-morbidities in venous thromboembolism patients}

Based on a review of the available records, 157 patients had a single co-morbidity, 81 had two co-morbidities, 23 had three co-morbidities, and 16 had four or more co-morbidities. About 21\% (114/549) of patients were "acutely medically ill" (myocardial infarction, heart failure, chronic obstructive pulmonary disease, ventilator dependency, sepsis, or pneumonia) [Table 4].

\section{Clinical presentation of venous thromboembolism}

Of the 476 patients with DVT, 2\% (9) had upper extremity DVT, 97\% (462) had lower extremity DVT and the site of DVT was not known in 5 patients. A total of $31 \%(143 / 462)$ patients had DVT in the right limb, $54 \%(249 / 462)$ in the left limb and 9\% (41/462) in both limbs (site not known in 29 patients). Of the 462 patients with lower extremity DVT, 61\% had proximal DVT, $13 \%$ had distal DVT, and 7\% had proximal and distal DVT. A total of 39\% (215/549) patients were diagnosed with VTE during their hospital stay, 54\% (296/549) were admitted to hospital with a diagnosis of VTE, and $7 \%(38 / 549)$ were diagnosed and continued to be managed in the outpatient department [Figure 2]. The duration of hospitalization after diagnosis of VTE is shown in Table 5.

A smaller proportion of patients $(15 \% ; 81 / 549)$ was diagnosed with VTE during the postoperative period. Figure 3 shows the proportion of patients with VTE at different time points during the postoperative period. Of those diagnosed beyond 6 weeks, 21\% (3/14) had orthopedic surgery (hip fracture surgery).

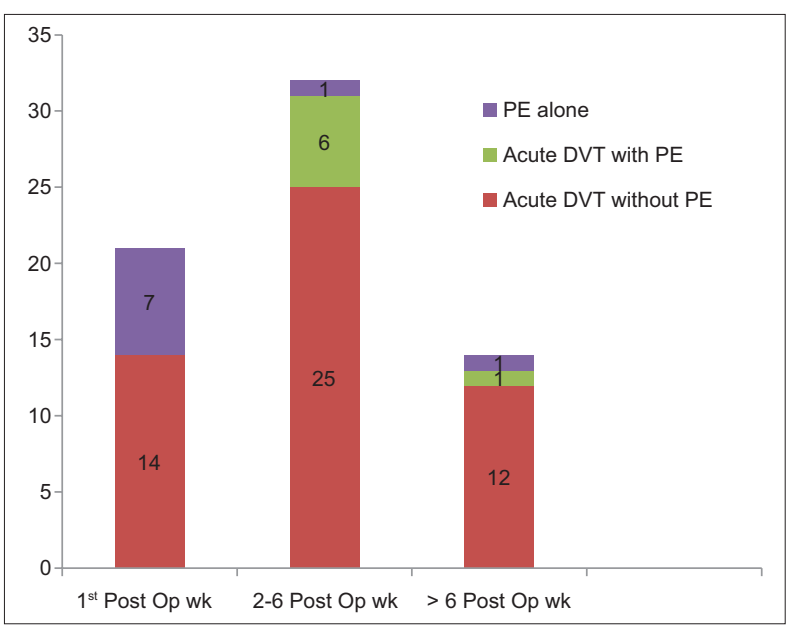

Figure 3: Diagnosis of venous thromboembolism during the postoperative period $(n=8 \mathrm{I})$ 
Table 3: Risk factors for venous thromboembolism

\begin{tabular}{|c|c|c|c|c|}
\hline Risk factor & $\begin{array}{l}\text { VTE patients } \\
(n=549), n(\%)\end{array}$ & $\begin{array}{l}\text { Acute DVT without } \\
\text { PE }(n=352), n(\%)\end{array}$ & $\begin{array}{l}\text { Acute DVT complicated } \\
\text { with PE }(n=124), n(\%)\end{array}$ & $\begin{array}{c}\text { Patients with PE } \\
\text { alone }(n=73), n(\%)\end{array}$ \\
\hline Past history of DVT & $189(34.4)^{\S}$ & $123(34.9)^{\S}$ & $65(52.4)$ & $\mathrm{I}(\mathrm{I} .4)$ \\
\hline Past history of PE & $46(8.4)^{* * *}$ & $5(1.4)$ & $30(24.2)$ & II (I5.I)*** \\
\hline Family history of VTE & $4(0.7)$ & $4(1.1)$ & 0 & 0 \\
\hline Total hip replacement & $2(0.4)$ & $2(0.6)$ & 0 & 0 \\
\hline Total knee replacement & $\mathrm{I}(0.2)$ & 0 & 0 & I (I.4) \\
\hline Hip fracture surgery & $14(2.6)$ & $10(2.8)$ & $2(1.6)$ & $2(2.7)$ \\
\hline Other orthopedic surgery* & $16(2.9)^{11}$ & $14(4.0)^{* * *}$ & $\mathrm{I}(0.8)$ & $\mathrm{I}(\mathrm{I} .4)$ \\
\hline Surgery ${ }^{\dagger}$ & $119(22)^{* * *}$ & $91(26)^{\prime \mid}$ & $16(13)$ & $12(16)$ \\
\hline Immobilization for $>3$ days & $76(13.8)^{\S}$ & $54(15.3)^{\S}$ & II (8.9) & II (I5.I) \\
\hline Received blood transfusion & $34(6.2)^{\S}$ & $30(8.5)^{\S}$ & $3(2.4)$ & I (I.4) \\
\hline Cancer ${ }^{\star}$ & $38(7)$ & $30(9)^{* * *}$ & $3(2)$ & $4(5)$ \\
\hline Ongoing radiation therapy for cancer & $3(0.5)$ & $3(0.9)$ & 0 & 0 \\
\hline Ongoing chemotherapy for cancer & $16(2.9)$ & $14(4)$ & I (0.8) & I (I.4) \\
\hline Trauma & $89(16.2)^{\S}$ & $59(16.8)^{\S}$ & $19(15.3)$ & II (I5.I) \\
\hline Hormone replacement therapy & 0 & 0 & 0 & 0 \\
\hline Pregnancy/postpartum & II (2) & $7(2)$ & $\mathrm{I}(\mathrm{I})$ & $3(4)$ \\
\hline Hormonal contraceptives & $2(0.4)$ & 0 & $\mathrm{I}(0.8)$ & $\mathrm{I}(\mathrm{I} .4)$ \\
\hline Long distance travel including air travel & $5(0.9)$ & $3(0.9)$ & $2(1.6)$ & 0 \\
\hline Varicose veins & $59(\mid 0.7)^{\prime \prime}$ & $43(\mid 2.2)^{\prime \prime}$ & $15(12.1)$ & $\mathrm{I}(\mathrm{I} .4)$ \\
\hline Intravenous drug abuse & 0 & 0 & 0 & 0 \\
\hline Indwelling central venous catheter & $32(5.8)^{\S}$ & $21(6.0)^{\S}$ & $4(3.2)$ & $7(9.6)$ \\
\hline Thrombophilia & $42(7.7)^{\S}$ & $18(5.1)^{\S}$ & $22(17.7)$ & $2(2.7)$ \\
\hline Elevated homocysteine level & $53(9.7)$ & $25(7.1)$ & $20(16.1)$ & $8(11.0)$ \\
\hline
\end{tabular}

*Other orthopedic surgery includes surgery other than TKR, THR and hip fracture surgery (significance value is mentioned for all orthopaedic surgeries together); ${ }^{\dagger}$ Surgery includes gastrointestinal, cardiovascular, obstetrics/gynaecological, general. Genito-urinary, neurological, oncology and bariatric surgeries; "Cancer includes gastrointestinal, genito-urinary, lung, breast, blood/lymphatic cancers; ${ }^{\circledR} P<0.000$; $\| P<0.005 ; * * P<0.05$. DVT: Deep vein thrombosis; VTE: Venous thromboembolism; PE: Pulmonary embolism; TKR: Total knee replacement; THR: Total hip replacement

Table 4: Co-morbidities in venous thromboembolism patients

\begin{tabular}{|c|c|c|c|c|}
\hline Co-morbidity & $\begin{array}{l}\text { VTE patients } \\
(n=549), n(\%)\end{array}$ & $\begin{array}{l}\text { Acute DVT without } \\
\text { PE }(n=352), n(\%)\end{array}$ & $\begin{array}{l}\text { Acute DVT complicated } \\
\text { with PE }(n=124), n(\%)\end{array}$ & $\begin{array}{c}\text { Patients with PE } \\
\text { alone }(n=73), n(\%)\end{array}$ \\
\hline Hypertension & $135(24.6)$ & $86(24.4)$ & $30(24.2)$ & $19(26.0)$ \\
\hline Diabetes mellitus & $105(19.1)$ & $70(19.9)$ & $18(14.5)$ & $17(23.3)$ \\
\hline Neurological disease (other than stroke) & $45(8.2)$ & $34(9.7)$ & $7(5.6)$ & $4(5.5)$ \\
\hline Stroke & $29(5.3)$ & $23(6.5)$ & I $(0.8)$ & $5(6.8)$ \\
\hline Myocardial infarction & $38(6.9)$ & $23(6.5)$ & $9(7.3)$ & $6(8.2)$ \\
\hline Heart failure & $12(2.2)$ & $9(2.6)$ & $3(2.4)$ & 0 \\
\hline COPD & II (2.0) & $7(2.0)$ & 0 & $4(5.5)$ \\
\hline Ventilator dependent & $18(3.3)$ & $8(2.3)$ & $2(1.6)$ & $8(\mathrm{II} .0)$ \\
\hline Sepsis & $16(2.9)$ & II (3.I) & $2(1.6)$ & $3(4.1)$ \\
\hline Obesity & $3 \mid(5.6)$ & II (3.I) & $14(|| .3)$ & $6(8.2)$ \\
\hline Pneumonia & $19(3.5)$ & $9(2.6)$ & $5(4.0)$ & $5(6.8)$ \\
\hline Inflammatory bowel disease & $\mathrm{I}(0.2)$ & 0 & I $(0.8)$ & 0 \\
\hline Severe dehydration & $3(0.5)$ & $3(0.9)$ & 0 & 0 \\
\hline
\end{tabular}

DVT: Deep vein thrombosis; VTE: Venous thromboembolism; PE: Pulmonary embolism; COPD: Chronic obstructive pulmonary disease

The most common (73\%) symptom was "swelling of the limb" among patients with VTE [Table 6].

\section{Management strategies for venous thromboembolism patients}

\section{Diagnostic tools for venous thromboembolism}

In merely $4 \%$ of all the patients, DVT was also confirmed by venography. PE was confirmed by pulmonary angiography in $27 \%$ of all the patients [Table 7].

\section{Anticoagulant treatment in venous thromboembolism}

A total of $94 \%$ (515/549) of patients were recommended anticoagulants. Heparin (low molecular weight heparin [LMWH]/unfractionated heparin [UFH]) alone, a combination of heparin (LMWH/UFH) and oral anticoagulant (warfarin), and fondaparinux sodium alone were recommended to $82 \%(420 / 515)$, $13 \%(66 / 515)$, and $2 \%(12 / 515)$ patients, respectively as initial anticoagulation. The rest of patients were recommended streptokinase, urokinase, or tissue plasminogen activator.

Five percent $(25 / 515)$ of patients were recommended LMWH alone, and 76\% (393/515) were recommended either warfarin or acenocoumarol alone for long-term anticoagulation. 
The median duration of initial anticoagulation was 5 days while that of long-term anticoagulation was 180 days (6 months).

Anticoagulants were needed to be stopped because of bleeding in only $2 \%(9 / 515)$ patients.

Clinical outcomes in VTE patients are mentioned in Tables 8 and 9 .

\section{Annual incidence of acute deep venous thrombosis including the trend over a period of 5 years}

The annual incidence of acute DVT $( \pm \mathrm{PE})$ increased from 2006 to 2010 at all the three sites [Figure 4]. However, a formal site-wise statistical analysis could not be performed to analyse trends in the incidence rates in acute DVT $( \pm \mathrm{PE})$ and PE alone as there were zero observations in some instances.

Table 5: Duration of hospitalization after diagnosis of venous thromboembolism

\begin{tabular}{|c|c|c|c|c|}
\hline Diagnosis of VTE & $\begin{array}{c}\text { VTE } \\
\text { patients }\end{array}$ & $\begin{array}{l}\text { Acute DVT } \\
\text { without PE }\end{array}$ & $\begin{array}{l}\text { Acute DVT } \\
\text { complicated } \\
\text { with PE }\end{array}$ & $\begin{array}{l}\text { Patients } \\
\text { with PE } \\
\text { alone }\end{array}$ \\
\hline $\begin{array}{l}\text { VTE diagnosed while } \\
\text { patient was in the hospital }\end{array}$ & $n=2 \mid I$ & $n=112$ & $n=44$ & $n=55$ \\
\hline Mean (minimum-maximum) & $9(0-50)$ & $9.6(0-50)$ & $8(1-38)$ & $8.4(1-34)$ \\
\hline $\begin{array}{l}\text { Patient was admitted into } \\
\text { hospital with a diagnosis } \\
\text { of VTE }\end{array}$ & $n=182$ & $n=113$ & $n=59$ & $n=10$ \\
\hline Mean (minimum-maximum) & $7.6(1-30)$ & $8.2(1-30)$ & $6.5(I-22)$ & $7.7(I-2 I)$ \\
\hline
\end{tabular}

\section{Discussion}

To our knowledge, this is the first multicenter, retrospective registry in India involving patients with VTE that reflect real-world clinical practice.

In contrast with the Western data in which VTE is predominantly a disease of older age, ${ }^{[11]} 44 \%$ patients in our study were between 40 and 59 years of age while $34 \%$ were below 40 years, particularly those with PE. In a study from North India, $80 \%$ of PE patients were below 50 years. ${ }^{[12]}$ Men constituted $70 \%$ of our registry, more than those reported from Vellore registry $(48 \%),{ }^{[13]}$ but similar to those reported in the ENDORSE (Epidemiologic

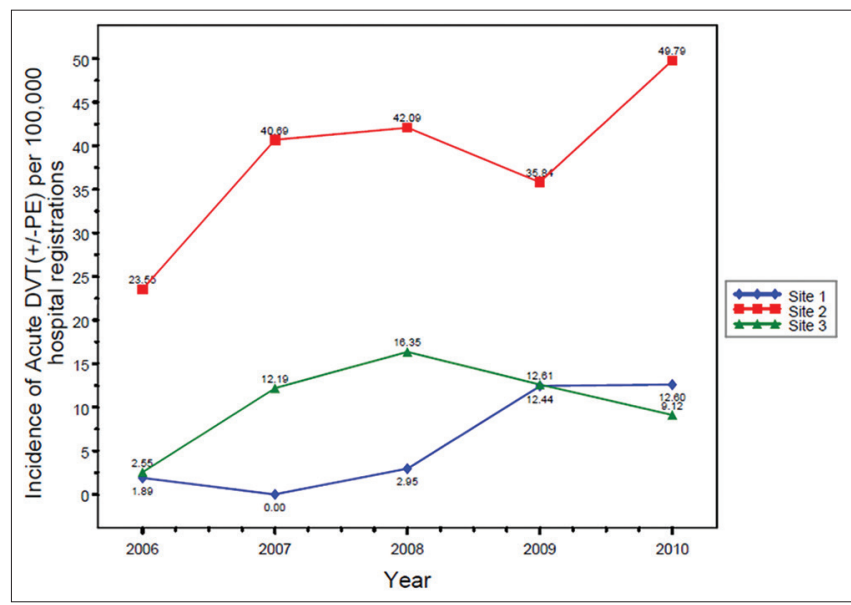

Figure 4: Incidence of acute deep vein thrombosis (with or without pulmonary embolism) over a 5 years period (2006-2010) at three sites

Table 6: Symptoms in venous thromboembolism patients

\begin{tabular}{lcccc}
\hline Symptom & $\begin{array}{c}\text { VTE patients } \\
(\boldsymbol{n}=\mathbf{5 0 4}), \boldsymbol{n}(\%)\end{array}$ & $\begin{array}{c}\text { Acute DVT without } \\
\text { PE }(\boldsymbol{n}=\mathbf{3 2 0}), \boldsymbol{n}(\%)\end{array}$ & $\begin{array}{c}\text { Acute DVT complicated } \\
\text { with PE }(\boldsymbol{n}=\text { I I 7), } \boldsymbol{n}(\%)\end{array}$ & $\begin{array}{c}\text { Patients with PE } \\
\text { alone }(\boldsymbol{n}=\mathbf{6 7}), \boldsymbol{n}(\%)\end{array}$ \\
\hline Swelling of limb & $366(72.6)$ & $286(89.4)$ & $71(60.7)$ & $9(13.4)$ \\
Extremity discomfort & $257(51)$ & $196(6 I .3)$ & $58(49.6)$ & $3(4.5)$ \\
Discoloration of limb & $43(8.5)$ & $38(I 1.9)$ & $5(4.3)$ & 0 \\
Erythema of limb & $38(7.5)$ & $36(11.3)$ & $2(1.7)$ & 0 \\
Dyspnoea & $189(37.5)$ & $49(15.3)$ & $86(73.5)$ & $54(80.6)$ \\
Chest pain & $77(15.3)$ & $19(5.9)$ & $35(29.9)$ & $23(34.3)$ \\
Cough & $67(13.3)$ & $15(4.7)$ & $26(22.2)$ & $26(38.8)$ \\
Syncope & $13(2.6)$ & 0 & $6(5.1)$ & $7(10.4)$ \\
Fever & $26(5.7)$ & $11(3.4)$ & $9(7.7)$ & $6(8.9)$ \\
\hline
\end{tabular}

DVT: Deep vein thrombosis; VTE: Venous thromboembolism; PE: Pulmonary embolism

Table 7: Diagnostic tools

\begin{tabular}{|c|c|c|c|c|}
\hline Test & $\begin{array}{l}\text { VTE patients } \\
(n=549), n(\%)\end{array}$ & $\begin{array}{l}\text { Acute DVT without } \\
\text { PE }(n=352), n(\%)\end{array}$ & $\begin{array}{l}\text { Acute DVT complicated } \\
\text { with PE }(n=124), n(\%)\end{array}$ & $\begin{array}{l}\text { Patients with PE } \\
\text { alone }(n=73), n(\%)\end{array}$ \\
\hline Venography for DVT & $20(3.6)$ & $14(4)$ & $5(4)$ & I* (I.4) \\
\hline CT scan for PE & $4 \mid(7.5)$ & $2(0.6)^{\dagger}$ & $20(16.1)$ & $19(26.0)$ \\
\hline V/Q scan for PE & $51(9.3)$ & $12(3.4)^{\dagger}$ & $25(20.2)$ & $14(19.2)$ \\
\hline Pulmonary angiography for $\mathrm{PE}^{\star}$ & $150(27.3)$ & $23(6.5)^{\dagger}$ & $84(67.7)$ & $43(58.9)$ \\
\hline
\end{tabular}

*Venography was done to exclude a diagnosis of associated PE; ${ }^{\dagger} \mathrm{CT}$ scan, V/Q scan and pulmonary angiography were done to exclude PE; ${ }^{*} \mathrm{CT}$ pulmonary angiography. DVT: Deep vein thrombosis; VTE: Venous thromboembolism; PE: Pulmonary embolism; CT: Computed tomography 


\begin{tabular}{|c|c|c|c|c|}
\hline Clinical outcome & $\begin{array}{l}\text { VTE patients } \\
(n=215), n(\%)\end{array}$ & $\begin{array}{l}\text { Acute DVT without } \\
\text { PE }(n=116), n(\%)\end{array}$ & $\begin{array}{l}\text { Acute DVT complicated } \\
\text { with PE }(n=44), n(\%)\end{array}$ & $\begin{array}{l}\text { Patients with PE } \\
\text { alone }(n=55), n(\%)\end{array}$ \\
\hline \multicolumn{5}{|c|}{ Discharged from hospital } \\
\hline Yes & $203(94.4)$ & $106(9 \mid .4)$ & $43(97.7)$ & $54(98.2)$ \\
\hline No & $12(5.6)$ & $10(8.6)$ & I (2.3) & I (I.8) \\
\hline \multicolumn{5}{|l|}{ Shifted to ICU } \\
\hline Yes & $105(48.8)$ & $29(25)$ & $30(68.2)$ & $46(83.6)$ \\
\hline No & $97(45.1)$ & $76(65.5)$ & $13(29.5)$ & $8(14.5)$ \\
\hline Not known & $13(6.0)$ & II (9.5) & I (2.3) & $\mathrm{I}(\mathrm{I} .8)$ \\
\hline \multicolumn{5}{|c|}{ Readmitted to hospital } \\
\hline Yes & $12(5.6)$ & $8(6.9)$ & $3(6.8)$ & $(1.8)$ \\
\hline No & $54(25.1)$ & 47 (40.5) & $3(6.8)$ & $4(7.3)$ \\
\hline Not known & $142(66.0)$ & $55(47.4)$ & $38(86.4)$ & $49(89.1)$ \\
\hline Not applicable & $7(3.3)$ & $6(5.2)$ & 0 & $\mathrm{I}(\mathrm{I} .8)$ \\
\hline \multicolumn{5}{|c|}{ Death during hospital stay } \\
\hline Yes & $16(7.4)$ & $13(1 \mid .2)$ & $2(4.5)$ & I (I.8) \\
\hline No & $199(92.6)$ & $103(88.8)$ & $42(95.5)$ & $54(98.2)$ \\
\hline
\end{tabular}

DVT: Deep vein thrombosis; VTE: Venous thromboembolism; PE: Pulmonary embolism; ICU: Intensive Care Unit

\begin{tabular}{|c|c|c|c|c|}
\hline Clinical outcome & $\begin{array}{l}\text { VTE patients } \\
(n=296), n(\%)\end{array}$ & $\begin{array}{l}\text { Acute DVT without } \\
\text { PE }(n=199), n(\%)\end{array}$ & $\begin{array}{l}\text { Acute DVT complicated } \\
\text { with PE }(n=79), n(\%)\end{array}$ & $\begin{array}{l}\text { Patients with PE } \\
\text { alone }(n=18), n(\%)\end{array}$ \\
\hline \multicolumn{5}{|c|}{ Discharged from hospital } \\
\hline Yes & $292(98.6)$ & $195(98)$ & $79(100)$ & $18(100)$ \\
\hline No & $3(1)$ & $3(1.5)$ & 0 & 0 \\
\hline Not known & $\mathrm{I}(0.3)$ & $\mathrm{I}(0.5)$ & 0 & 0 \\
\hline \multicolumn{5}{|l|}{ Shifted to ICU } \\
\hline Yes & $103(34.8)$ & $50(25.1)$ & $44(55.7)$ & $9(50)$ \\
\hline No & $189(63.9)$ & $146(73.4)$ & $35(44.3)$ & $8(44.4)$ \\
\hline Not known & $4(1.4)$ & $3(1.5)$ & 0 & I (5.6) \\
\hline \multicolumn{5}{|c|}{ Readmitted to hospital } \\
\hline Yes & $21(7.1)$ & $12(6)$ & $7(8.9)$ & $2(I I . I)$ \\
\hline No & $4 \mid(13.9)$ & $38(19.1)$ & $2(2.5)$ & I (5.6) \\
\hline Not known & $234(79.1)$ & $149(74.9)$ & $70(88.6)$ & $15(83.3)$ \\
\hline \multicolumn{5}{|c|}{ Death during hospital stay } \\
\hline Yes & $3(1.0)$ & $3(1.5)$ & 0 & 0 \\
\hline No & $292(98.6)$ & $195(98)$ & $79(100)$ & $18(100)$ \\
\hline Not known & I (0.3) & $\mathrm{I}(0.5)$ & 0 & 0 \\
\hline
\end{tabular}

DVT: Deep vein thrombosis; VTE: Venous thromboembolism; PE: Pulmonary embolism; ICU: Intensive Care Unit

International Day for the Evaluation of Patients at Risk for VTE in the Acute Hospital Care Setting) study (69\%). ${ }^{[14]}$ One of the reasons for this could be significantly high levels of homocysteine (thrombophilia marker) in males as compared to females as reported in an Indian study. ${ }^{[15]}$ Fewer Indian women use oral contraceptives and postmenopausal hormone replacement therapy, which are known to be risk factors for thrombosis. This is supported by the fact that only $1 \%$ of women in this registry reported the use of oral contraceptives, and none reported use of hormonal replacement therapy.

A total of $28 \%$ of the overall referrals were from cardiologists. The majority $(82 \%)$ of the referrals were from medical rather than surgical $(15 \%)$ specialties as against a referral rate of $93 \%$ from surgeons at Vellore. ${ }^{[13]}$ Our finding complements that from the ENDORSE study ${ }^{[14]}$ in which $55 \%$ of the medical patients at risk of VTE had cardiovascular disease. Majority (53\%) of patients in our study had co-morbid cardiovascular disease including diabetes mellitus; it is possible that these patients visited a cardiologist for their cardiovascular ailment (s) and were then referred by the cardiologist to vascular disease specialist (investigator). DVT without PE was mostly referred by family/general physicians. Most (89\%) of these patients had swelling of the (lower) limb. It is possible that these patients may not have felt the need to visit a specialist for a symptom like "swelling of limb," instead visited their family physician. It is very encouraging to know that family physicians suspected DVT in these situations and referred the patient to a specialist.

Patients with a history of VTE are about 8 times more likely to develop a new episode during a subsequent high-risk period compared with patients without a 
history of DVT or PE. ${ }^{[16]}$ Prior history of DVT was the most $(34 \%)$ common risk factor in patients who had only DVT, whereas past history of PE, trauma, and immobilization for more than 3 days were the most common risk factors in patients who had only PE. Patients undergoing orthopedic surgery constituted 22\% (33/152) of all surgical patients. Six percent patients received blood transfusion while $5 \%$ patients had obstetrics/ gynecological surgeries. Our results (major lower limb surgery as a risk factor in 3\% patients) appear to be consistent with those reported in the ENDORSE study, which reported DVT in $4.4 \%$ patients undergoing major lower limb surgery. ${ }^{[14]}$ Other studies from India have reported a DVT incidence rate ranging from $8 \%$ to $20 \%$ in major lower limb surgery. ${ }^{[17,18]}$ Malignancy has been reported as a risk factor in $31 \%$ patients. ${ }^{[13]}$ However, in our study, only $7 \%$ of patients had malignancy as a predisposing factor. Among the malignancies, genitourinary cancer had the highest incidence (45\%).

Hypertension (25\%) was the most common co-morbidity followed by diabetes mellitus (19\%) in this patient population. In addition, obesity $(11 \%)$ was a common risk factor in DVT complicated by PE. Our findings support an Asian (Korean) study that demonstrated prevalence of the metabolic syndrome in $48 \%$ patients with VTE. ${ }^{[19]}$ Co-morbid neurological disease (other than stroke) and ventilator dependency were also commonly found in patients with DVT $(10 \%)$ and PE (11\%) respectively. Both these conditions immobilize patients for prolonged periods of time, predisposing them to VTE. About 21\% of patients were acutely medically ill.

Venography and pulmonary angiography are the gold standard for diagnosis of DVT and PE respectively. ${ }^{[20]}$ In our study, venography was used in just $4 \%$ patients and pulmonary angiography in less than one-third of the patients. Perhaps the relatively high cost of these tests and limited availability of such procedures may be the limiting factors. Doppler ultrasonography still remains the widespread diagnostic modality for detecting VTE in India.

Overall, most (93\%) patients were managed as inpatients $39 \%$ diagnosed with VTE during hospital stay and $54 \%$ admitted to hospital with a diagnosis of VTE). PE was mostly (75\%) diagnosed during hospital stay. A mean duration of hospitalization of 7-9 days after diagnosis of VTE is supported by published data. ${ }^{[21]}$ In selected low-risk patients, outpatient treatment of DVT and PE may be considered. ${ }^{[22-24]}$ This approach was observed in a small proportion (7\%) of patients who were managed on an outpatient basis, nearly all (97\%) of whom had only DVT.
The reported prevalence of postsurgical VTE in our study $(15 \%)$ was half of that $(30 \%)$ reported in Vellore registry. ${ }^{[13]}$ This could be explained by higher referral rate from surgeons at Vellore compared to that of our sites. Most $(40 \%$; 32/81) DVT cases were diagnosed between 2 and 6 postoperative weeks, but PE in most cases (70\%; $7 / 10$ ) was diagnosed during the first postoperative week. We notice that acute DVT complicated by PE was less $(6 \%$; $7 / 124)$ frequently diagnosed during the postoperative period as against $18 \%(64 / 352)$ and $14 \%(10 / 73)$ of acute DVT alone and PE alone, respectively.

Anticoagulants are the mainstay of treatment for VTE. The use and duration of anticoagulants in our registry appears to be consistent with the American College of Chest Physicians treatment guidelines, ${ }^{[25]}$ which recommend at least 5 days of initial anticoagulation with parenteral anticoagulation (LMWH, fondaparinux, intravenous UFH, or subcutaneous UFH) and at least 3 months of long-term anticoagulation treatment with Vitamin K antagonist.

Bleeding is the most serious complication of anticoagulation treatment and is a major concern for clinicians particularly as the patient's age advances. In this registry, anticoagulant treatment was needed to be stopped because of bleeding in only $2 \%$ of the study population. The prospective REITE registry has reported a rate of $3 \%$ for major/fatal bleeds. ${ }^{[2]}$ Thus, the fear of bleeding complications, which decreases the use of anticoagulant treatment, appears to be minimal.

Almost all (97\%) hospitalized patients were discharged from hospital. DVT complicated by PE $(60 \%)$ and PE alone (75\%) were more frequently shifted to Intensive Care Unit than those who had DVT alone (25\%). Similar to published data in which hospital readmission rate for VTE was 5\% for primary and $14 \%$ for secondary diagnosis, ${ }^{[27]}$ we report a hospital readmission rate of $6 \%$; however we do not know the cause for readmission.

Overall $4 \%$ of hospitalized patients died. The death rate was $7 \%$ among those diagnosed with VTE during hospital stay as against a rate of $1 \%$ among those who were hospitalized with a diagnosis of VTE. Over $90 \%$ of patients treated on an outpatient basis obtained symptomatic relief with treatment. In our study, the hospital discharge rate $(97 \%)$ was more than triple and death rate was a quarter of that reported by Pandey et al. ${ }^{[28]}$ (hospital discharge rate $31 \%$ and death rate $16 \%)$ at a university hospital in Delhi. 
Our data show a significant increase in acute DVT $( \pm \mathrm{PE})$ from 2006 to 2010 . This can be explained by the increased awareness of VTE in India as well as the advent of better diagnostic modalities, such as duplex ultrasonography becoming more readily available and accepted. Although there was no significant change in the number of PE cases from 2006 to 2010, the burden of PE is almost double (13\% of all VTE) of $7 \%$, rate reported at Christian Medical College, Vellore during a 10-year period from 1996 to $2005 .{ }^{[13]}$ Our finding is consistent with a study from North India that reported a 16\% incidence of PE in adult medical autopsies. ${ }^{[12]}$

This study has the expected limitations of any retrospective review including the availability of complete records for all patients, although a robust review of the data on medical charts was conducted. Controlling for bias and confounders is difficult as there is no randomization and no blinding. Follow-up data of patients after hospital discharge were not available. In cases of death, the exact cause of death was not mentioned on medical records. Further, the clinic charts reviewed in this study included a mix of those from Vascular Surgery and Hematology Departments, limiting the generalizability of the study results. Despite these limitations, this study provides large amount of useful information in a short span of time on patient characteristics, clinical outcomes, management strategies, and temporal trends in VTE, based on "real world" data that reflect actual day-to-day clinical practice over a period of 5 years across three sites in India. We believe that this information will serve as a guide in the optimal implementation of VTE prophylaxis and treatment, to improve patient outcomes and to decrease the occurrence of VTE in India.

\section{Conclusion}

Real world data reflecting actual day-to-day clinical practice in VTE over a period of 5 years across three sites in India showed that VTE is not uncommon in Indian patients and that acute DVT was responsible for the substantial burden of VTE. Bleeding was not the limiting factor for anticoagulant treatment in most patients. We believe that this information will serve as a guide in the optimal implementation of VTE prophylaxis and treatment, to improve patient outcomes and to decrease the occurrence of VTE in India.

\section{Acknowledgments}

This study was funded by GlaxoSmithKline Pharmaceuticals, Mumbai, Maharashtra, India. All listed authors meet the criteria for authorship set forth by the International Committee for Medical Journal Editors. The authors wish to acknowledge Dr. Ramakrishna Pinjala (Department of Vascular Surgery, Nizam's Institute of Medical Sciences, Hyderabad - 500 082, Telangana, India) and Dr. Rajiv Parakh (Division of Peripheral Vascular and Endovascular Sciences, Medanta - The Medicity, New Delhi, India) for their inputs in developing the study protocol, Dr. Jeroze Dalal for operational oversight to the study, Ms. Samuda Kanakapura for monitoring the conduct of the study and Dr. Sujay Kulkarni for critical review and assistance during the development of this manuscript. Dr. Jeroze Dalal, Ms. Samuda Kanakapura, and Dr. Sujay Kulkarni are full-time employees of GlaxoSmithKline Pharmaceuticals Limited.

\section{Financial support and sponsorship}

This study was funded by GlaxoSmithKline Pharmaceuticals, Mumbai, Maharashtra, India.

\section{Conflicts of interest}

Dr. Liesel C. Dsilva is and Dr. Sadhna J. Joglekar was full-time employee of GlaxoSmithKline Pharmaceuticals Limited.

\section{References}

1. Cohen AT, Agnelli G, Anderson FA, Arcelus JI, Bergqvist D, Brecht JG, et al. Venous thromboembolism (V'TE) in Europe. The number of VTE events and associated morbidity and mortality. Thromb Haemost 2007;98:756-64.

2. White RH. The epidemiology of venous thromboembolism. Circulation 2003;107 23 Suppl 1:I4-8.

3. Kahn SR, Ginsberg JS. The post-thrombotic syndrome: Current knowledge, controversies, and directions for future research. Blood Rev 2002;16:155-65.

4. Pengo V, Lensing AW, Prins MH, Marchiori A, Davidson BL, Tiozzo F, et al. Incidence of chronic thromboembolic pulmonary hypertension after pulmonary embolism. N Engl J Med 2004;350:2257-64.

5. Kapoor VK. Venous thromboembolism in India. Natl Med J India 2010;23:193-5.

6. Cronan JJ, Dorfman GS, Grusmark J. Lower-extremity deep venous thrombosis: Further experience with and refinements of US assessment. Radiology 1988;168:101-7.

7. Stulberg BN, Insall JN, Williams GW, Ghelman B. Deep-vein thrombosis following total knee replacement. An analysis of six hundred and thirty-eight arthroplasties. J Bone Joint Surg Am 1984;66:194-201.

8. Lee LH, Gu KQ, Heng D. Deep vein thrombosis is not rare in Asia - The Singapore General Hospital experience. Ann Acad Med Singapore 2002;31:761-4.

9. Dhillon KS, Askander A, Doraismay S. Postoperative deep-vein thrombosis in Asian patients is not a rarity: A prospective study of 88 patients with no prophylaxis. J Bone Joint Surg Br 1996;78:427-30.

10. Agarwala S, Bhagwat AS, Modhe J. Deep vein thrombosis in Indian patients undergoing major lower limb surgery. Indian J Surg 2003;65:159-62.

11. Silverstein MD, Heit JA, Mohr DN, Petterson TM, O'Fallon WM, Melton L.J $3^{\text {rd }}$. Trends in the incidence of deep vein thrombosis and 
pulmonary embolism: A 25-year population-based study. Arch Intern Med 1998;158:585-93.

12. Kakkar N, Vasishta RK. Pulmonary embolism in medical patients: An autopsy-based study. Clin Appl Thromb Hemost 2008;14:159-67.

13. Lee AD, Stephen E, Agarwal S, Premkumar P. Venous thrombo-embolism in India. Eur J Vase Endovase Surg 2009;37:482-5.

14. Pinjala R; ENDORSE-India investigators. Venous thromboembolism risk \& prophylaxis in the acute hospital care setting (ENDORSE), a multinational cross-sectional study: Results from the Indian subset data. Indian J Med Res 2012;136:60-7.

15. Pai N, Ghosh K, Shetty S. Cause of deep venous thrombosis and pulmonary embolism in young patients from India as compared with other ethnic groups. Blood Coagul Fibrinolysis 2012;23:257-61.

16. Samama MM. Epidemiology of risk factors of deep venous thrombosis (DVT) of the lower limbs in community practice: The SIRIUS study. Thromb Haemost 1993;69:763.

17. Nagi ON, Dhillon MS, Katariya S, Mujeeb SM. Deep vein thrombosis after major surgery-evaluation by compression ultrasonography. Indian J Orthop 1999;33:200-3.

18. Sharma H, Maini L, Agrawal N, Upadhyay A, Vishwanath J, Dhaon BK. Incidence of deep vein thrombosis in patients with fractures around hip joint: A prospective study. Indian J Orthop 2002;36:5.

19. Jang MJ, Choi WI, Bang SM, Lee T, Kim YK, Ageno W, et al. Metabolic syndrome is associated with venous thromboembolism in the Korean population. Arterioscler Thromb Vase Biol 2009;29:311-5.

20. Dupras D, Bluhm J, Felty C, Hansen C, Johnson T, Lim K, et al. Institute for Clinical Systems Improvement. Venous Thromboembolism Diagnosis and Treatment. Available from: http://www.bit.ly/ VTE0113. [Last updated on $2013 \mathrm{Jan}$ ].

21. White RH, Zhou H, Romano PS. Length of hospital stay for treatment of deep venous thrombosis and the incidence of recurrent thromboembolism. Arch Intern Med 1998;158:1005-10.
22. Levine M, Gent M, Hirsh J, Leclere J, Anderson D, Weitz J, et al. A comparison of low-molecular-weight heparin administered primarily at home with unfractionated heparin administered in the hospital for proximal deep-vein thrombosis. N Engl J Med 1996;334:677-81.

23. Koopman MM, Prandoni P, Piovella F, Ockelford PA, Brandjes DP, van der Meer J, et al. Treatment of venous thrombosis with intravenous unfractionated heparin administered in the hospital as compared with subcutaneous low-molecular-weight heparin administered at home. The Tasman Study Group. N Engl J Med 1996;334:682-7.

24. Janjua M, Badshah A, Matta F, Danescu LG, Yaekoub AY, Stein PD. Treatment of acute pulmonary embolism as outpatients or following early discharge. A systematic review. Thromb Haemost 2008; 100:756-61.

25. Kearon C, Akl EA, Comerota AJ, Prandoni P, Bounameaux H, Goldhaber SZ, et al. Antithrombotic therapy for VTE disease: Antithrombotic therapy and prevention of thrombosis, $9^{\text {th }}$ ed: American College of Chest Physicians Evidence-Based Clinical Practice Guidelines. Chest 2012;141 2 Suppl:e419S-94S.

26. Nieto JA, Solano R, Ruiz-Ribó MD, Ruiz-Gimenez N, Prandoni P, Kearon C, et al. Fatal bleeding in patients receiving anticoagulant therapy for venous thromboembolism: Findings from the RIETE registry. J Thromb Haemost 2010;8:1216-22.

27. Spyropoulos AC, Lin J. Direct medical costs of venous thromboembolism and subsequent hospital readmission rates: An administrative claims analysis from 30 managed care organizations. J Manag Care Pharm 2007;13:475-86.

28. Pandey A, Patni N, Singh M, Guleria R. Assessment of risk and prophylaxis for deep vein thrombosis and pulmonary embolism in medically ill patients during their early days of hospital stay at a tertiary care center in a developing country. Vase Health Risk Manag 2009;5:643-8.

\section{Notice}

Dear ISCCM members,

Greetings from ISCCM office!

We have been celebrating ISCCM Day every year with a theme. The theme of ISCCM Day for this year is "Patient Safety in the ICU".

Poster is a good method for making doctors and lay people aware of Patient safety in the ICU. Taking the opportunity of the ISCCM day celebration, we are announcing a Poster competition on "Patient Safety in the ICU".

Top 2 posters will receive a citation from society and prize of Rs 10,000 and Rs 7,500 respectively.

Instructions for submission of Poster on "Patient Safety in the ICU"

1. Ensure that poster is catered to Indian setup

2. It should be original and not copied from somewhere else

3. Should be in poster format

4. Words allowed-up to 100 maximum

5. Should be in English

Last day for submission is $10^{\text {th }}$ September 2016 and it should be emailed to Dr. Vijaya Patil, Secretary ISCCM and Chairman, ISCCM Day Committee, ISCCM at vijayappatil@yahoo.com

We welcome any other suggestions from our members.

With warm regards

Dr. Atul Kulkarni

President - ISCCM
Dr. Kapil Zirpe

President - Elect, ISCCM
Dr. Pradip Kumar Bhattacharya

General Secretary ISCCM
Dr. Vijaya Patil

Secretary ISCCM, Chairman, ISCCM Day Committee, ISCCM 